\title{
Nanoindentation of Phase and Structural Components of Pallasite Seymchan (PMG)
}

Evgenia Brusnitsina, Razilia Muftakhetdinova, Grigoriy Yakovlev, and Victor Grokhovsky

Mira str., 19, Ekaterinburg, Russian Federation

\section{Abstract}

Determination of mechanical properties in multiphase bodies of extraterrestrial origin is a fundamental task. In this work the hardness and Young's modulus in the Seymchan pallasite were determined in kamacite $\alpha-\mathrm{Fe}(\mathrm{Ni}, \mathrm{Co})$, taenite $\gamma$-Fe $(\mathrm{Ni}, \mathrm{Co})$, plessite $(\alpha+\gamma)$, tetrataenite FeNi using nanoindentation technique. For the first time, the hardness and modulus of elasticity of a two-phase nanostructure of cloudy zone $\mathrm{FeNi}+\alpha-\mathrm{Fe}(\mathrm{Ni}, \mathrm{Co})$, formed as a result of very slow cooling (about $1 \mathrm{~K} / \mathrm{Myr}$ ), was determined.

Keywords: Seymchan pallasite, indentation, Young's modulus, hardness, Fe-Ni alloys, cloudy zone, tetrataenite.

Evgenia Brusnitsina

jeka_bru@list.ru

Received: 25 February 2019

Accepted: 9 April 2019

Published: 15 April 2019

Publishing services provided by Knowledge E

(c) Evgenia Brusnitsina et al. This article is distributed under the terms of the Creative Commons

Attribution License, which permits unrestricted use and redistribution provided that the original author and source are credited.

Selection and Peer-review under the responsibility of The Ural school-seminar of metal scientists-young researchers Conference Committee.

\section{Introduction}

Meteorites are one of the most valid evidence of the bombardment of the Earth by small bodies and the most accessible extraterrestrial substance for laboratory research. Thus, fragments of meteorites are the only material available on Earth to evaluate, although approximate, the physical and mechanical properties of meteoroids [1].

Nanoindentation is one of the modern methods for studying the local mechanical properties of various materials. Of great interest is the application of this method in studies of metal alloys and compounds with a finely dispersed structure. In meteorites, such structures are formed during very slow cooling of the order of $1 \mathrm{~K} / \mathrm{Myr}$ of Fe-Ni alloy with a low Co content (no more than 1\%) [2]. In the meteoritic metal, the following phases and structures are distinguished: kamacite $\alpha-\mathrm{Fe}(\mathrm{Ni}, \mathrm{Co})$, the $\mathrm{Ni}$ content varies from $4 \%$ to $7.5 \%$; taenite $\mathrm{Y}$-Fe (Ni, Co), $\mathrm{Ni}$ content from $7.5 \%$ to $50 \%$; tetrataenite $\gamma^{\prime}$ - is a FeNi compound with an ordered $L 1_{0}$ structure; martensite $\alpha_{2}$, plessite $(\alpha+\gamma)$ with different morphology and fine two-phase region $\gamma^{\prime}+\alpha-\mathrm{Fe}(\mathrm{Ni}, \mathrm{Co})$, which is called the cloudy zone.

Previously, the Vickers microhardness method was used to determine the mechanical characteristics of the structural components of the meteorite metal. This method in the 
study of the microstructure of iron meteorites and pallasites was used to support optical and electron microscopy [3-5]. In [3], average values for Vickers microhardness $\alpha-F e$ $(\mathrm{Ni}, \mathrm{Co})$ and $\mathrm{y}-\mathrm{Fe}(\mathrm{Ni}, \mathrm{Co})$ in various meteorites are given. The authors of [4] give the Vickers microhardness distribution in a metal particle of Krasnojarsk pallasite. In the early 90s [6], the nanoindentation method was used to study the unusual structure in the Tishomingo meteorite. Using this method, it was possible to establish the hardness and elastic modulus of martensite and taenite $\gamma-\mathrm{Fe}(\mathrm{Ni}, \mathrm{Co})$, the size of which was about 10 microns. Microhardness, the ratio of elastic and plastic deformation, the modulus of elasticity in individual minerals (kamacite, taenite, troilite, phosphide and silicate matrix [7]) were determined for iron meteorites Sikhote-Alin, Chinga, Dronino, Canyon Diablo, Lombard, using the method of "kinetic indentation" with Berkovich indenter. Using the method of nanoindentation, the local mechanical characteristics of the mineral components of the Chelyabinsk meteorite [8] were investigated. For silicates, sulfide FeS, and metal phases $\alpha-\mathrm{Fe}(\mathrm{Ni}, \mathrm{Co})$ and $\gamma-\mathrm{Fe}(\mathrm{Ni}, \mathrm{Co})$, the elastic modulus, hardness, and elastic recovery were determined.

In previous works, the nanoindentation method did not determine the mechanical characteristics for the structure of the zonal taenite, which consists of the following areas: compound FeNi $\left(\gamma^{\prime}\right)$ with an ordered $\mathrm{L}_{0}$ structure (tetrataenite); two-phase region, the socalled cloudy zone $\gamma^{\prime}+\alpha-\mathrm{Fe}(\mathrm{Ni}, \mathrm{Co})$. The size of these zones does not exceed several microns and can be investigated using only local methods.

Tetrataenite $\gamma^{\prime}(\mathrm{FeNi})$ is found mainly in the meteoritic substance and is formed from $\mathrm{Y}$ - $\mathrm{Fe}(\mathrm{Ni}, \mathrm{Co})(\mathrm{fcc}, \mathrm{A} 1)$ taenite. Therefore, the synthesis and research of this compound are significantly complicated. So far, the formation of an ordered structure of $\mathrm{L1}_{0} \mathrm{FeNi}$ in laboratory conditions has been reported only in samples subjected to irradiation with high-energy neutrons and electrons [9] and recently in thin films [10]. The main source of material for the study of tetrataenite are meteorites, in which for millions of years they manage to go through the processes of ordering.

The high interest in the study of tetrataenite is currently due to its unique magnetic properties [11]. However, the determination of the mechanical characteristics of this mineral is not satisfied. Only in one of the first studies on tetrataenite [5] by the Vickers method with a load of 25 grams, the grain hardness of tetrataenite was measured in the Estherville mesosiderate, which was 170 - $200 \mathrm{HV}$.

In the concentration range from 30 to $42 \mathrm{wt} . \% \mathrm{Ni}$, a fine two-phase region $(\alpha+\gamma)$ is observed, presumably formed as a result of spinodal decomposition [2]. The round light particles $\gamma^{\prime}(\mathrm{FeNi})$ are located in the dark $\alpha-\mathrm{Fe}(\mathrm{Ni}, \mathrm{Co})$ matrix (Fig. 2, b), this structure is also called the "cloudy zone" by analogy with light clouds in the dark sky. This structure 
was first described in [12]. Using transmission electron microscopy, the sizes of highnickel particles were determined and diffraction patterns were obtained.

The purpose of this work is to study the mechanical properties of various phases and structures in the Seymchan meteorite (PMG). The study of the mechanical properties of the zonal taenite is of particular interest.

\section{Experimental Details}

In this paper, we investigated a fragment of the Seymchan meteorite, which belongs to the class of pallasites. Both silicates and metal regions are present in its structure. Meteorite metal is an alloy of $\mathrm{Fe}-\mathrm{Ni}$, which is formed during extremely slow cooling (about $1 \mathrm{~K} / \mathrm{Myr}$ ). As a result, a unique structure with nanoscale particles is formed. The nanoindentation method is perfectly suited for determining the mechanical characteristics of nanostructures. This method allows to explore the fine structure of a meteorite metal without destroying it.

The sample was grinded and polished using the standard technique. Polished sections were etched by Nital ( $2-4 \mathrm{vol} \% \mathrm{HNO}_{3}$ solution in ethanol). An optical microscope Axiovert 40 MAT and scanning electron microscope Carl Zeiss SIGMA VP with an EDS unit to determine the chemical composition were used to study the microstructure of the metal part of the meteorite. Measurements of nanohardness and modulus of elasticity were performed on a Hysitron TI 750 Ubi instrument, in which the trihedral Berkovich pyramid was used as an indenter.

Nanoindentation was carried out in four areas (Fig. 1, a): 1) kamacite $\alpha$-Fe (Ni, Co); 2) taenite $\gamma$ - $\mathrm{Fe}(\mathrm{Ni}, \mathrm{Co}) 2$ ) plessite $(\alpha+\gamma)$; and 4) zonal taenite - a light gray rim on the $\alpha /$ $\gamma$ border, in which, at a higher magnification, a tetrataenite band $\gamma$ '(FeNi) about $2 \mu \mathrm{m}$ wide and a cloudy zone - (FeNi $+\alpha-\mathrm{Fe}(\mathrm{Ni}, \mathrm{Co}))$ are observed (Fig. 1, b).

Nanoindentation of the areas of kamacite $(\alpha)$, plessite $(\alpha+\gamma)$ and taenite $(\gamma)$ was carried out with a load of $7 \mathrm{mN}, 25$ measurements with a step of $10 \mu \mathrm{m}$ were performed in each area. In the area of zonal taenite (section 4 in Fig. 1, a), 100 measurements were performed with a step of $2.5 \mu \mathrm{m}$ and a load of $1 \mathrm{mN}$. The chemical composition was determined using the EDS unit at three points in each region of interest.

\section{Results and Discussion}

The image of the microstructure of the investigated metal part of the Seymchan meteorite is shown in Fig. 1, a. The metal particle (light area) is surrounded by silicates (dark 
area). $\alpha-\mathrm{Fe}(\mathrm{Ni}, \mathrm{Co})($ kamacite) and $\mathrm{\gamma}-\mathrm{Fe}(\mathrm{Ni}, \mathrm{Co})$ (taenite) are distinguishable in an optical microscope after etching. Highly etched structure represents plessite area, a fine mixture of two phases $(\alpha+\gamma)$. It was formed as a result of martensitic transformation and then disintegrated: $\gamma \rightarrow \alpha_{2} \rightarrow \alpha+\gamma$ [13]. At the $\alpha / \gamma$ boundary, one can find a light gray rim, in which, at a higher magnification (Fig. 1b), it is possible to distinguish a band of tetrataenite with a width of about $2 \mu \mathrm{m}$ and a cloudy zone (FeNi $+\alpha-\mathrm{Fe}(\mathrm{Ni}, \mathrm{Co}))$.

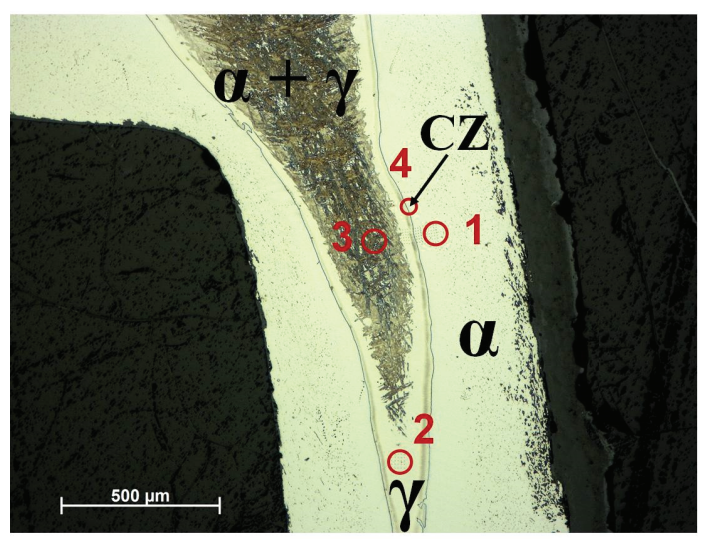

(a)

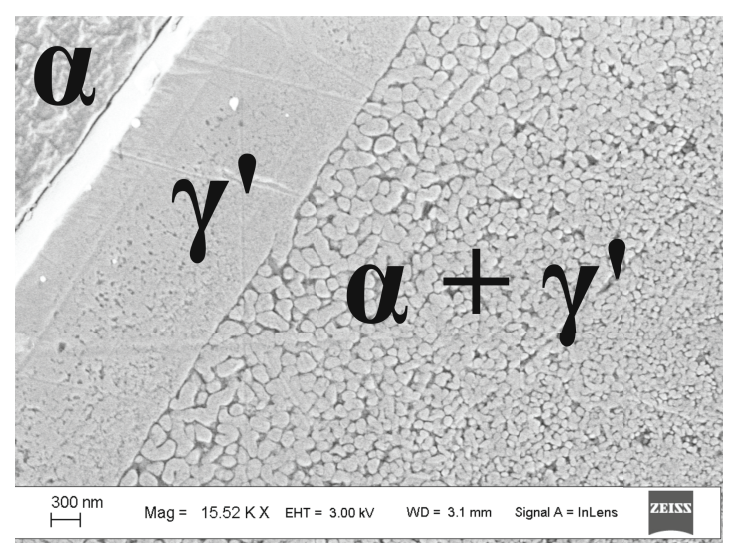

(b)

Figure 1: The structure of the investigated metal particle in the Seymchan meteorite: a) optical image with measurement areas 1 - $\alpha-\mathrm{Fe}(\mathrm{Ni}, \mathrm{Co}), 2$ - $\gamma$ - $\mathrm{Fe}(\mathrm{Ni}, \mathrm{Co}), 3-(\alpha+\gamma), 4$ - zoned taenite; b) SEM image of area №4 tetrataenite $\gamma^{\prime}(\mathrm{FeNi})$ and $\mathrm{CZ}$ - cloudy zone $\left(\alpha+\gamma^{\prime}\right)$.

The average values of hardness $\mathrm{H}$, modulus of elasticity $\mathrm{E}$ and chemical composition for areas 1 - 3 are given in table 1.

TABLE 1: Average mechanical properties and chemical composition of Seymchan meteorite phase and structural components in case of nanoidentation with $7 \mathrm{mN}$ loading.

\begin{tabular}{|l|c|c|c|c|c|}
$\begin{array}{l}\text { Region of } \\
\text { interest }\end{array}$ & Phase & $\mathrm{H}, \mathrm{GPa}$ & $\mathrm{E}, \mathrm{Gpa}$ & $\mathrm{Ni}$, weight \% & Fe, weight \% \\
\hline 1 & $\alpha-\mathrm{Fe}(\mathrm{Ni}, \mathrm{Co})$ & 3,55 & 241 & 7,1 & 92,1 \\
\hline 2 & $\mathrm{\gamma}-\mathrm{Fe}(\mathrm{Ni}, \mathrm{Co})$ & 3,98 & 67 & 21,7 & 77,7 \\
\hline 3 & Plessite $\alpha+\gamma$ & 4,22 & 219 & 15,1 & 84,1 \\
\hline
\end{tabular}

The table 1 shows that the hardness of the $\gamma$-phase is slightly higher than the hardness of the $\alpha$-phase, however, the elastic modulus of the $\alpha$-phase is 3 times higher than that of the $\gamma$-phase. The region 3 is the hardest, since it has a two-phase fine structure. The values for $\alpha$-phase and $\gamma$-phase are comparable with the results obtained for the same phases in the Chelyabinsk meteorite using nanoindentation [8].

The results of the study of area 4 are presented in table 2 . The SEM images of the investigated structures are shown in Figure 2. It can be seen that the hardness values obtained for the $\alpha$ phase with nanoindentation with a load of $1 \mathrm{mN}$ are slightly higher than with nanoindentation with a load of $7 \mathrm{mN}$. It seems that the scale factor, which we have not estimated in this work, is a reason for that phenomenon. 
TABLE 2: Average mechanical properties of Seymchan meteorite phase and structural components in case of nanoidentation with $1 \mathrm{mN}$ loading.

\begin{tabular}{|l|c|c|c|}
\hline Region of interest & Phase & H, GPa & E, Gpa \\
\hline 4 & tetrataenite $\gamma^{\prime}($ FeNi) & 8,43 & 237 \\
\hline 4 & $\left(\alpha+\gamma^{\prime}\right)$ cloudy zone & 7,23 & 208 \\
\hline
\end{tabular}

As can be seen from the tables 1 and 2 , the hardness of $\gamma^{\prime}(\mathrm{FeNi})$ is two times higher than the hardness of the $\gamma$-phase, this feature is characteristic of ordered structures. The scale factor during nanoindentation also can results in observed difference.

To compare the obtained results with the data from [5], the Berkovich hardness value $(\mathrm{HIT})$ of tetrataenite was converted to the Vickers hardness value (HV), based on the coefficients proposed in the article [14]. Results of our measurements of the tetrataenite hardness values are several times higher than the values measured previously. This difference can be explained by the scale factor during dispersed structures measurements in standard Vickers hardness tests. Also in [5], a large particle $\gamma^{\prime}(\mathrm{FeNi})$ was studied, which apparently formed by a mechanism different from formation of our region of interest.

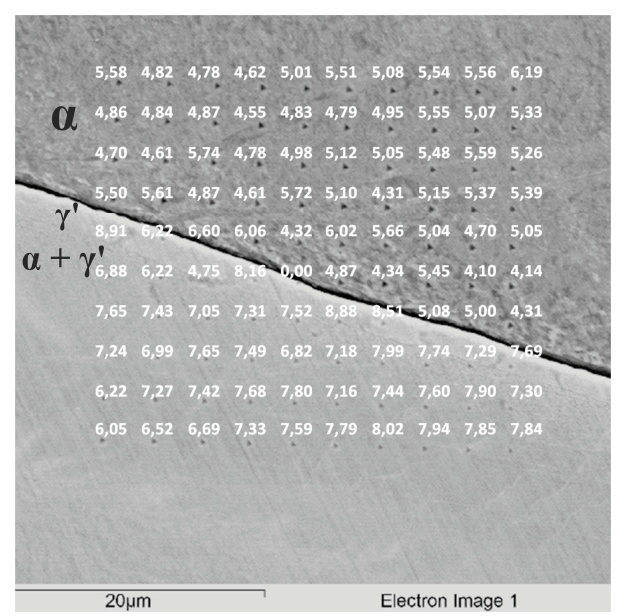

(a)

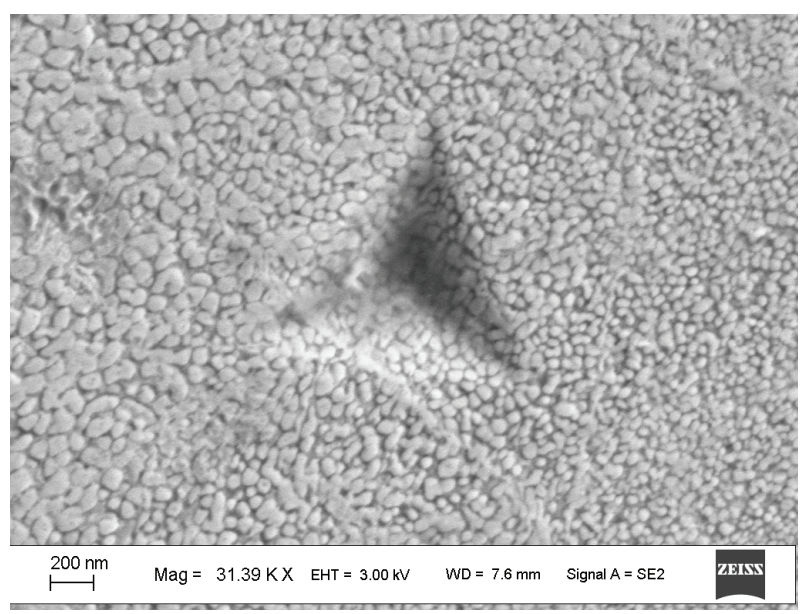

(b)

Figure 2: Nanoindentation of the metal particle in Seymchan pallasite: a) values of hardness in the cloudy zone $\left(\alpha+\gamma^{\prime}\right)$, tetratenite FeNi $\gamma^{\prime}$ and the borderline kamasite $\alpha-\mathrm{Fe}(\mathrm{Ni}, \mathrm{Co})$; b) mark of the indenter in the cloudy zone $\left(\alpha+\gamma^{\prime}\right)$.

For the first time, the hardness and elastic modulus of a two-phase nanostructure, cloudy zone $(\mathrm{FeNi}+\alpha-\mathrm{Fe}(\mathrm{Ni}, \mathrm{Co}))(\mathrm{Fig} .2, \mathrm{~b})$, were determined. The values of the mechanical characteristics of the cloudy zone are slightly lower than for $\gamma^{\prime}(\mathrm{FeNi})$. This may be due to the presence of the $\alpha$-phase in the structure, which lowers the total value of hardness and elastic modulus. 


\section{Conclusions}

The application of the nanoindentation technique allowed us to determine the mechanical characteristics of various phases and structural components in the Seymchan meteorite. At the same time, our measurements were non-destructive. Same samples can be examined by various other methods. The main results obtained in the work are:

1. Using the nanoindentation method, for the first time, we determined the mechanical characteristics of $\gamma^{\prime}(\mathrm{FeNi})$. The average value of the $\gamma^{\prime}$-phase hardness is 8.43 GPa, the elastic modulus - $237 \mathrm{GPa}$.

2. For the first time, the mechanical characteristics of a two-phase nanoscale region $(\alpha+\gamma)$, the so-called cloudy zone, were determined. The average value of hardness $\left(\alpha+\gamma^{\prime}\right)$ is $7.23 \mathrm{GPa}$, the elastic modulus - $208 \mathrm{GPa}$.

3. The role of the scale factor in case of nanoindentation with low loads should be estimated.

4. The presented results are one of the first steps in the application of nanoindentation as a technique to determine the mechanical properties of metallic nanostructures in meteorites formed as a result of very slow cooling (about $1 \mathrm{~K} / \mathrm{Myr}$ ).

\section{Acknowledgments}

The reported study was funded by RFBR according to the research project № 1838-00598 and the Ministry of Education and Science of the Russian Federation (The projects 5.4825.2017/6.7, 5.3451.2017/4.6).

\section{References}

[1] J. J. Petrovic., Review Mechanical properties of meteorites and their constituents, Journal of material science. 36 (2001) 1579-1583.

[2] C.-W. Yang, D. B. Williams, J. I. Goldstein, A revision of the Fe-Ni Phase Diagram at low temperature $\left(<400^{\circ} \mathrm{C}\right)$, Phase Equilibrium. 17 (1996) 522-531.

[3] V.F. Buchwald, Handbook of Iron Meteorites, The Regents of the University of California, 1975.

[4] T. B. Massalski, F. R. Park, A study of four pallasites using metallographic, microhardness and microprobe techniques, Geochim. et Cosmichim. Acta. 28 (1964) $1165-1175$. 
[5] R. S. J. Clarke, E. R. D. Scott, Tetrataenite - ordered FeNi, a new mineral in meteorites, American Mineralogist. 65 (1980) 624-630

[6] K. F. Russel, E. A. Kenik, M. K. Miller, Characterization of the Tishomingo meteorite, Surface Science. 246 (1991) $292-298$.

[7] E.S. Kozlovskikh, V.I. Grokhovsky, Micromechanical properties of basic minerals of meteorites, Minerals: structure, properties, research methods, materials of the $2 \mathrm{nd}$ All-Russian Youth Scientific Conference (Miass, March 23-26, 2010)., 198-200.

[8] C. E. Moyano-Cambero, E. Pellicer, J. M. Trigo-Rodríguez, et al., Nanoindenting the Chelyabinsk Meteorite to Learn about Impact Deflection Effects in asteroids, The Astrophysical Journal. 835 (2017) 9.

[9] L.M. Neel, J. Pauleve, R. Pauthenet, J. Laugier, D. Dautreppe, Magnetic properties of an iron-nickel single crystal ordered by neutron bombardment, Journal of Applied Physics. 35 (1964) 873-876.

[10] T. Kojima, M. Ogiwara, M. Mizuguchi, M. Kotsugi, T. Koganezawa, T. Ohtsuki, et al., Fe-Ni composition dependence of magnetic anisotropy in artificially fabricated $\mathrm{L}_{0}$ ordered FeNi films, Journal of Physics: Condensed Matter. 26 (2014) 64207.

[11] L.H. Lewis, F.E. Pinkerton, N. Bordeaux, A. Mubarok, E. Poirier, J.I. Goldstein, et al., De magnete et meteorite: cosmically motivated materials, Magn. Lett. 5 (2014) 5500104.

[12] R. A. Jago, Santa Catharina and the origin of cloudy taenite in meteorites, Nature. 279 (1979) 413-415.

[13] J. Zhang, D.B. Williams, J.I. Goldstein, Decomposition of Fe-Ni Martensite: Implications for the Low-Temperature $\leq 500^{\circ} \mathrm{C}$ Fe-Ni Phase Diagram, Metallurgical and Materials Transactions. 25A (1994) 1627 - 1637.

[14] D.J. Ma, J.L. Wang, L. Sun, Y. Huang, Method for Identifying Vickers Hardness by Instrumented Indentation Curves with Berkovich/Vickers Indenter, Experimental Mechanics. 56 (2016) 891 - 900. 